\title{
Quantitative Analysis of Gly m Bd 28K in Soybean Products by a Sandwich Enzyme-Linked Immunosorbent Assay
}

\author{
Noriko Bando, ${ }^{1, *}$ Hideaki Tsuj, ${ }^{2}$ Miki Hiemori, ${ }^{1}$ \\ Kazuma Yoshizumi, ${ }^{1}$ Rintaro Yamanishi, ${ }^{1}$ \\ Masumi Kiмото $^{2}$ and Tadashi OgawA ${ }^{1,3}$ \\ ${ }^{1}$ Department of Nutrition, School of Medicine, The University of Tokushima, \\ Tokushima 770-8503, Japan \\ ${ }^{2}$ Department of Nutritional Science, Faculty of Health and Welfare Science, \\ Okayama Prefectural University, Soja 719-1197, Japan \\ ${ }^{3}$ Research Institute for Food Science, Kyoto University, \\ Uji 611-0011, Japan
}

(Received March 10, 1998)

\begin{abstract}
Summary A sandwich enzyme-linked immunosorbent assay for the soybean allergen, which consists of a monoclonal antibody (D4) as the fixing (first) antibody and another peroxidase-conjugated monoclonal antibody (C5) as the second, has been developed. Both D4 and C5 monoclonal antibodies strongly bound to the guanidine/ $\mathrm{HCl}$-denatured allergen, Gly $\mathrm{m}$ Bd $28 \mathrm{~K}$. Therefore the samples used in the present experiment were extracted with sodium phosphate buffer $(\mathrm{pH} 8.0)$ containing $6 \mathrm{~m}$ guanidine and $10 \mathrm{~mm}$ 2-mercaptoethanol, then completely dialyzed against phosphate-buffered saline (PBS). The dialyzed samples were subjected to the assay. Various soybean products were observed to contain the allergen at high concentrations, such as soybean protein isolate (SPI), tofu, kori-dofu, and yuba, but its contents in soy milk and abura-age were found to be low. In fermented products such as natto, soy sauce, and miso, and even in the processed foods with soybean protein isolate (SPI), the allergen was not detected. These results were also confirmed by an immunoblotting technique with D4.
\end{abstract}

Key Words soybean, soybean allergen, Gly m Bd 28K, sandwich enzymelinked immunosorbent assay

Soybean is a major protein source in Japanese food, and it is also known to be a representive allergic food causing such syndromes as atopic dermatitis. We systematically investigated allergens in soybeans and showed that Gly $\mathrm{m} \mathrm{Bd} 68 \mathrm{~K}$ ( $\alpha$-subunit of $\beta$-conglycinin), Gly m Bd 30K (34 kDa-oil-body-associated protein), and Gly $\mathrm{m} \mathrm{Bd} 28 \mathrm{~K}$ are the major allergens in soybean seeds (2). Gly $\mathrm{m} \mathrm{Bd} 68 \mathrm{~K}$

* To whom correspondence should be addressed. 
and Gly $\mathrm{m}$ Bd $30 \mathrm{~K}$ have been studied (2-4). Gly $\mathrm{m}$ Bd $28 \mathrm{~K}$ has recently been purified by use of a monoclonal antibody (mAb, C5) against the allergen and characterized (1). For the development of hypoallergenic soybean products, the establishment of an analytical method to determine their allergen contents and their characterization are inevitable. We therefore prepared two mAbs against Gly $\mathrm{m}$ $\mathrm{Bd} 30 \mathrm{~K}$ and used them to develop a sandwich enzyme-linked immunosorbent assay (ELISA) for Gly m Bd 30K (5). However, no analytical method for Gly m Bd 28K, one of the main allergens, has been established.

In this report, we describe the development of a sandwich ELISA for Gly m $\mathrm{Bd} 28 \mathrm{~K}$. Furthermore, the amounts of the allergen in various soybean products were measured by the sandwich ELISA.

\section{MATERIALS AND METHODS}

Materials. The materials used in the present study were obtained from the sources indicated: mouse myeloma cell line, P3 × 63Ag8U1 (P3U1) (Shino Test Institute, Sagamihara, Japan); BALB/c mice (SLC, Shizuoka, Japan); complete and incomplete Freund's adjuvant (Nakalai Tesque, Kyoto, Japan); fetal bovine serum, sterilized L-glutamine and streptomycin-penicillin mixture (MA Bioproducts, CA, USA); RPMI 1640 (Nissui Phermaceutical, Tokyo, Japan); a mouse monoclonal antibody isotyping kit (Amersham International PLC, Amersham, UK); aminopterin (Sigma, MO, USA); polyethyleneglycol 4000 (Merck, Darmstadt, Germany); prepared protein A column and nitrocellulose membrane (Bio-Rad, CA, USA); lysyl endopeptidase from Achromobacter lyticus M 497-1 (Promega, Madison, WI, USA); peroxidase-conjugated sheep anti-mouse IgG and IgM (Organon Teknika, West Chester, PA, USA); mouse IgG (Zymed Laboratories, CA, USA); mouse IgM (Bethyl, Montgomery, TX, USA); electrophoresis calibration kit (Pharmacia, Uppsala, Sweden); peroxidase (Sigma); defatted soybean flakes and soybean protein isolate (SPI) (Fuji Oil, Osaka, Japan).

Preparation of Gly $m B d 28 \mathrm{~K}$. Gly $\mathrm{m} \mathrm{Bd} 28 \mathrm{~K}$ was prepared in the same manner as described earlier (1). Briefly, proteins in defatted flakes were extracted

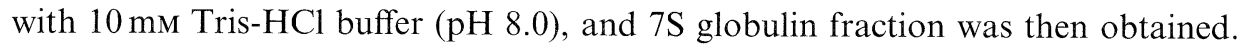
The $7 \mathrm{~S}$ globulin proteins were fractionated with ammonium sulfate. The precipitate formed from $50 \%$ to $70 \%$ saturation was dialyzed against $10 \mathrm{~mm}$ Tris- $\mathrm{HCl}$ buffer ( $\mathrm{pH}$ 8.0). The dialysate was subjected to affinity (C5-Sepharose), ion-exchange (DEAE-Sepharose 6B), and gel-filtration (Sephacryl S-200) chromatographies, successively. The purified allergen obtained as described above was shown to be homogenous on SDS-PAGE. The allergen was used as the antigen or the authentic Gly $\mathrm{m}$ Bd $28 \mathrm{~K}$ in this work.

Preparation of $m A b$. One of the two mAbs against Gly $m$ Bd $28 \mathrm{~K}$ used for the present sandwich ELISA, C5, had been obtained previously (1). To develop a sandwich ELISA for Gly $\mathrm{m} \mathrm{Bd} 28 \mathrm{~K}$, another mAb had to be produced. Therefore a hybridoma producing a suitable $\mathrm{mAb}$ for the sandwich ELISA was prepared in 
the same manner as described earlier (6), except that the antigen was used instead of the partially purified allergen. The hybridoma obtained was intraperitoneally injected into female BALB/c mice primed with pristane. After 10 to $14 \mathrm{~d}$, the ascitic fluids that had formed were collected. The mAb was partially purified from the ascitic fluids by precipitation with ammonium sulfate $(0-50 \%$ saturation). This $\mathrm{mAb}$ was named D4 and used in the present study.

Binding of the $m A b s$ to the allergen. The purified allergen was denatured by dialysis at $4^{\circ} \mathrm{C}$ overnight against $50 \mathrm{~mm}$ potassium phosphate buffer $(\mathrm{pH} 8.0)$ containing $6 \mathrm{~m}$ guanidine and $10 \mathrm{~mm} 2$-mercaptoethanol, followed by dialysis against phosphate-buffered saline (PBS). One hundred microliters of the dialysate obtained $(15 \mu \mathrm{g} / \mathrm{mL})$ was added to the wells of a 96-well microplate and incubated at $37^{\circ} \mathrm{C}$ for $2 \mathrm{~h}$. After being blocked with $1 \%$ gelatin in PBS and washing with PBS, the proteins on the well were treated with various concentrations of C5 or D4. C5 or D4 bound to the allergen was reacted with peroxidase-conjugated anti-mouse IgG or IgM, respectively. The immunocomplexes formed on the wells were incubated for $30 \mathrm{~min}$ at room temperature with $O$-phenylenediamine $(0.4 \mathrm{mg} / \mathrm{mL})$ and $0.01 \%$ $\mathrm{H}_{2} \mathrm{O}_{2}$ in $25 \mathrm{~mm}$ citrate/phosphate buffer ( $\mathrm{pH} 5.0$ ), and the absorbances of the reaction mixtures in the wells at $492 \mathrm{~nm}$ were determined with a microplate reader Model 450 (Bio-Rad).

Preparation of samples for sandwich enzyme-linked immunosorbent assay (ELISA). Soybean seeds, soybean products, or processed foods including SPI $(2 \mathrm{~g}$ or $10 \mathrm{~g})$ were homogenized in $50 \mathrm{~mL}$ of $50 \mathrm{~mm}$ sodium phosphate buffer $(\mathrm{pH}$ 8.0) containing $6 \mathrm{~m}$ guanidine and $10 \mathrm{~mm}$ 2-mercaptoethanol (buffer A) with a Polytron homogenizer and centrifuged at $10,000 \times g$ for $30 \mathrm{~min}$. The precipitates were washed three times with the same buffer. These supernatants were combined and used as samples for the sandwich ELISA. The samples were shown to contain only a small amount of the allergen, but a high concentration of the other proteins, which were considered to interfere with a precise assay of the allergen. Therefore a bulk interfering proteins was removed from the sample with a gel filtration. To determine the elution profile of the allergen, the purified allergen mixed with soybean extract was subjected to a Sephacryl S-200 column $(\phi 1.1 \times 65 \mathrm{~cm})$ and eluted with buffer $\mathrm{A}$. The allergen in each fraction was detected with the sandwich ELISA, and the fractions containing the allergen (fraction No. $23-27,1 \mathrm{~mL} /$ fraction) were pooled and concentrated by ultrafiltration through a Diaflo YM1 membrane filter. The concentrate was then dialyzed against PBS overnight at $4^{\circ} \mathrm{C}$. The samples to be analyzed were chromatogrammed and treated under the same conditions described above, then used for the ELISA experiment.

Sandwich ELISA. Peroxidase-conjugated C5 used in the sandwich ELISA system for the allergen was prepared according to the method of Nakane and Kawaoi (7). One hundred microliters of D4 $(25 \mu \mathrm{g} / \mathrm{mL})$ were added to the wells of a 96-well microplate and incubated at $37^{\circ} \mathrm{C}$ for $2 \mathrm{~h}$. The wells were blocked with $1 \%$ gelatin in PBS at $37^{\circ} \mathrm{C}$ for $1 \mathrm{~h}$, then washed three times with PBS. The wells were incubated with the extracts at $37^{\circ} \mathrm{C}$ for $1 \mathrm{~h}$ and washed three times with PBS 
containing $0.05 \%$ Tween 20 (PBS/Tween). The allergen bound to D4 on the wells was further reacted with peroxidase-conjugated C5 $(16.4 \mu \mathrm{g} / \mathrm{mL})$. The immunocomplexes on the wells were analyzed as mentioned above.

Sodium dodecyl sulfate-poly acrylamide gel electrophoresis (SDS-PAGE) and immunoblotting. In this experiment, the buffer used for the preparation of the sample contained $6 \mathrm{~m}$ guanidine, which is known to react with SDS in electrode buffer to form SDS-guanidine complex and the complex precipitates. Therefore guanidine in the sample was removed by dialysis against PBS containing $6 \mathrm{M}$ urea and $10 \mathrm{~mm}$ 2-mercaptoethanol. A dialyzed sample solution was mixed with an equal volume of the sample buffer, and the mixture was heated for $5 \mathrm{~min}$ in a boiling water bath. The sample prepared was applied on a $15 \%$ polyacrylamide gel. After SDS-PAGE, the proteins separated on the gel were electrophoretically transferred onto nitrocellulose membrane. The membrane was blocked with $1 \% \mathrm{BSA}$ in $20 \mathrm{~mm}$ Tris- $\mathrm{HCl}$ buffer ( $\mathrm{pH} 7.4$ ) containing $0.15 \mathrm{M} \mathrm{NaCl}$ and $0.05 \%$ Tween 20 and incubated at $37^{\circ} \mathrm{C}$ for $1 \mathrm{~h}$ with D4. The bound D4 (IgM) was reacted with peroxidaseconjugated sheep antimouse IgM. The immunocomplexes on the membranes were detected by a 30-min incubation at room temperature with 4-chloro-1-naphthol and $\mathrm{H}_{2} \mathrm{O}_{2}$ as the substrates. The immunoblotting of the products obtained by the lysyl endopeptidase digestion was done as follows. Intact allergen $(30 \mu \mathrm{g})$ was digested at $30^{\circ} \mathrm{C}$ for $5 \mathrm{~h}$ with lysyl endopeptidase $(1: 100$ lysyl endopeptidase to the allergen, by weight), as described in a previous paper (8). The proteolytic products were applied to SDS-PAGE and electrophoretically transferred onto nitrocellulose membrane, as described above. The peptides on the membrane were immunoblotted with $\mathrm{C} 5$ or D4. The bound $\mathrm{C} 5$ or D4 was reacted with peroxidase-conjugated sheep anti-mouse $\operatorname{IgG}$ or anti-mouse $\operatorname{IgM}$ and assayed by the same manner as described above.

\section{RESULTS AND DISCUSSION}

\section{Preparation of $m A b$}

The $\mathrm{mAb} \mathrm{C} 5$ had been prepared and characterized in the previous paper (1). Its light chains were $\kappa$, and the heavy chains were $\gamma 1\left(\operatorname{IgG}_{1}\right)$. A cell line producing another $\mathrm{mAb}(\mathrm{D} 4)$ against the allergen has been established in the present study. The light and heavy chains of D4 were $\kappa$ and $\mu$, respectively $(\operatorname{IgM})$. Both mAbs were shown to bind to the guanidine-denatured allergen. The concentration of $\mathrm{C} 5$ or D4 that gave the half of maximum absorbance on this sandwich ELISA was estimated to be $1.6 \times 10^{-10}$ and $2 \times 10^{-10} \mathrm{M}$ (Fig. 1). However, the allergen that was denatured with SDS showed less affinity to C5 than the guanidine-denatured allergen. To examine whether the two mAbs bind to the same epitope on the allergen, the allergen was digested with lysyl endopeptidase. The proteolytic products were immunoblotted with the mAbs (Fig. 2). D4 was shown to bind with the 24.5-, 21.0-, and 19.7-kDa peptides besides the original allergen. C5 showed no clear binding profiles to all the proteolytic products. These findings suggested that the 

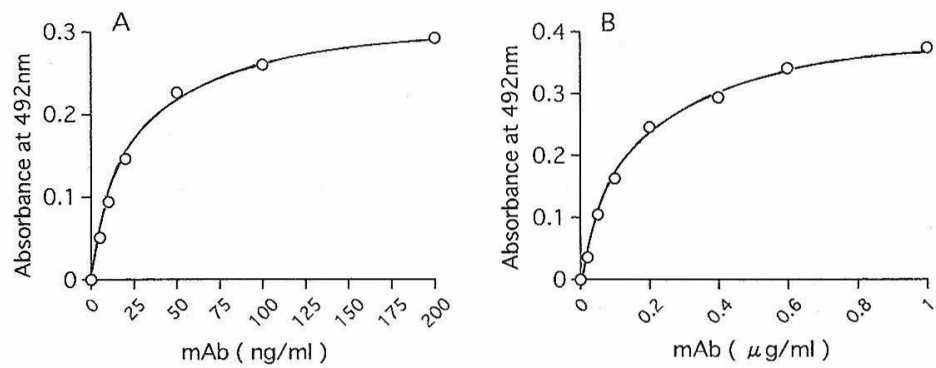

Fig. 1. Binding of C5 (A) and D4 (B) to the allergen, which was dialyzed against $50 \mathrm{~mm}$ phosphate buffer containing $6 \mathrm{M}$ guanidine. After the removal of guanidine from the dialysate by extensive dialysis against PBS, the dialysate was subjected to experiments for the binding of the mAbs. The condition was described in the text.

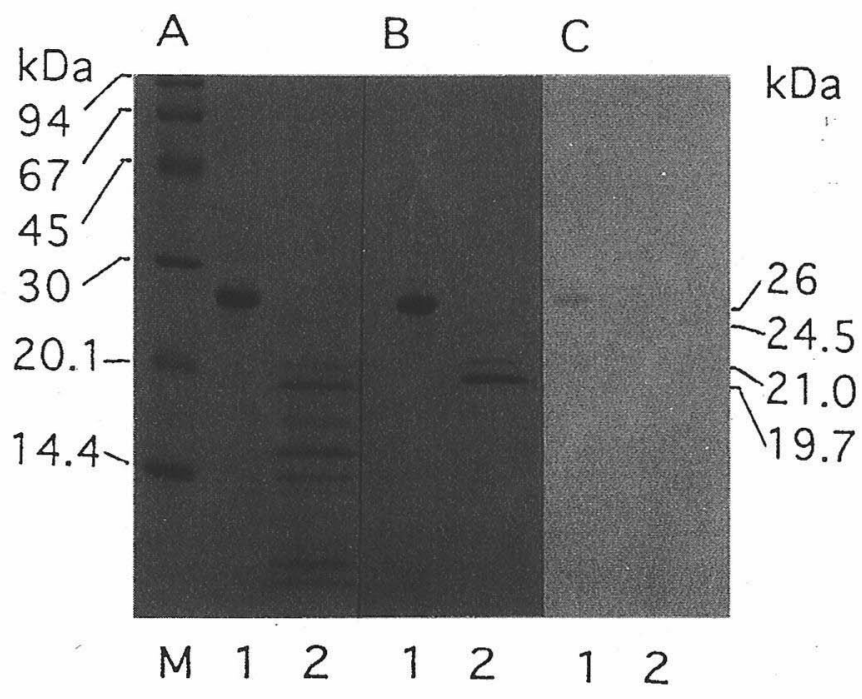

Fig. 2. Immunoblots of the proteolytic products obtained from Gly $\mathrm{m}$ Bd $28 \mathrm{~K}$. After SDS-PAGE, the intact allergen and the proteolytic products were electrophoretically transferred onto nitrocellulose membranes. The protein and the peptides on the membrane were immunoblotted with D4 or C5 (A: stained with Amido Black 10B, B: immunoblotted with D4, C: immunoblotted with C5). M, standard proteins; 1 , the intact allergen; 2, the products of the allergen digested with lysyl endopeptidase. The standard proteins used were as follows: phosphorylase $\mathrm{b}(94 \mathrm{kDa})$, bovine serum albumin $(67 \mathrm{kDa})$, ovalbumin $(45 \mathrm{kDa})$, carbonic anhydrase $(30 \mathrm{kDa})$, soybean trypsin inhibitor $(20.1 \mathrm{kDa}), \alpha$-lactoglobulin $(14.4 \mathrm{kDa})$.

two mAbs recognize the distinct epitopes on the allergen and demonstrated that they can be used in a sandwich ELISA system. 


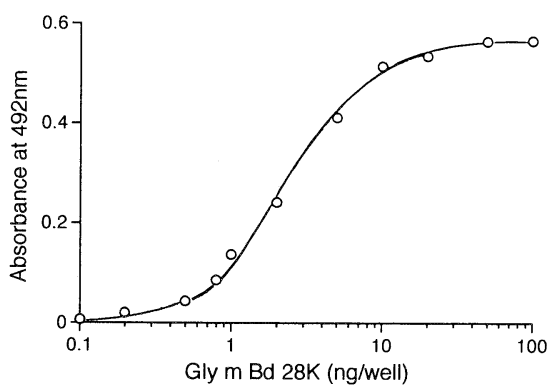

Fig. 3. Dose response curve of allergen in the sandwich ELISA. The sandwich ELISA was carried out as described in the text.

Table 1. Extraction of proteins from soybean products.

\begin{tabular}{lc}
\hline \multicolumn{1}{c}{ Products } & Yield $(\%)$ \\
\hline Soybean seeds & 96.2 \\
SPI & 99.5 \\
Soy milk & 94.8 \\
Tofu & 100.0 \\
Kori-dofu & 98.6 \\
Yuba & 95.1 \\
Abura-age & 92.4 \\
Miso & 80.8 \\
Shoyu & 100.0 \\
Natto & 90.2 \\
Meatballs & 35.9 \\
Beef croquettes & 89.6 \\
Fried chicken & 91.4 \\
Fish sausage & 88.3 \\
Hamburger & 69.9 \\
\hline
\end{tabular}

Extraction procedures were described in the text. After extraction, the extracts were centrifuged at 10,000 rpm for $30 \mathrm{~min}$ and the precipitate obtained was washed with PBS several times to remove guanidine. The nitrogen contents of the original sample and the precipitate were measured by the AOAC method (11). Yield was estimated by the following equation:

Yield $(\%)=\frac{\text { nitrogen in the original sample }- \text { nitrogen in the precipitate }}{\text { nitrogen in the original sample }} \times 100$.

Development of sandwich ELISA for Gly $m$ Bd $28 K$

We examined in detail the conditions suitable for a sandwich ELISA of Gly $\mathrm{m} \mathrm{Bd} 28 \mathrm{~K}$. Finally, the sandwich ELISA system described in the materials and methods was established. As Fig. 3 shows, 0.2 to $20 \mathrm{ng}$ of the allergen could be favorably determined by this method. 
Table 2. Contents of Gly $\mathrm{m} \mathrm{Bd} 28 \mathrm{~K}$ in soybean products.

\begin{tabular}{lcc}
\hline \multirow{2}{*}{ Products } & \multicolumn{2}{c}{ Gly m Bd $28 \mathrm{~K}$} \\
\cline { 2 - 3 } & $(\mu \mathrm{g} / \mathrm{g}$ fresh weight $)$ & $(\mu \mathrm{g} / \mathrm{g}$ nitrogen $)$ \\
\hline Soybean seeds & $4.35 \pm 0.47$ & $66.4 \pm 7.2$ \\
SPI & $14.41 \pm 0.98$ & $141.4 \pm 10.2$ \\
Soy milk & $0.14 \pm 0.01$ & $26.2 \pm 2.1$ \\
Tofu (momen $)$ & $0.28 \pm 0.03$ & $58.6 \pm 4.8$ \\
Kori-dofu & $4.62 \pm 0.54$ & $63.9 \pm 7.5$ \\
Yuba & $4.37 \pm 0.23$ & $54.6 \pm 2.9$ \\
Abura-age & $0.55 \pm 0.11$ & $15.5 \pm 3.0$ \\
Miso & n.d.* & n.d. \\
Shoyu & n.d. & n.d. \\
Natto & n.d. & n.d. \\
Meatballs & n.d. & n.d. \\
Beef croquettes & n.d. & n.d. \\
Fried chicken & n.d. & n.d. \\
Fish sausage & n.d. & n.d. \\
Hamburger & n.d. & n.d. \\
\hline
\end{tabular}

* Not detected.

\section{Analyses of Gly $m$ Bd $28 K$ in soybean products}

Before the analyses of the allergen in soybean products by the sandwich ELISA, the extraction procedures for proteins from soybean products were investigated. As described in the previous paper (8), Tris- $\mathrm{HCl}$ buffer containing SDS is effective for the extraction of proteins in the soybean products. Because C5 used in the ELISA system had less affinity for the allergen denatured in the presence of SDS, the buffer system of $50 \mathrm{~mm}$ potassium phosphate buffer $(\mathrm{pH} \mathrm{8.0)}$ containing $6 \mathrm{M}$ guanidine and $10 \mathrm{~mm} 2$-mercaptoethanol was employed. As shown in Table 1, it was demonstrated that this buffer system was effective for a quantitative extraction of the proteins in the soybean products, except for meatballs. The extract was subjected to the chromatography on a Sephacryl S-200 column to remove a bulk of proteins other than allergen. The recovery of the allergen from the gel filtration was estimated to be $92.7 \%$ by the addition of the isolated Gly $\mathrm{m} \mathrm{Bd} 28 \mathrm{~K}$ as an internal standard.

Using the above-mentioned sandwich ELISA, we determined the amount of Gly $\mathrm{m} \mathrm{Bd} 28 \mathrm{~K}$ in various soybean products (Table 2 ). The allergen was shown to occur at high concentrations in SPI, kori-dofu, and yuba, as found in soybean seeds. The allergen contents of soybean seeds, tofu (momen), kori-dofu, and yuba were shown to be almost the same values from one another based on nitrogen contents. These results suggest that most of the allergen in the original soybean seeds remains without its destruction or reduction during processing. Soy milk and abura-age also contained significant amounts of the allergen. A soy milk sold Vol 44, No 5, 1998 


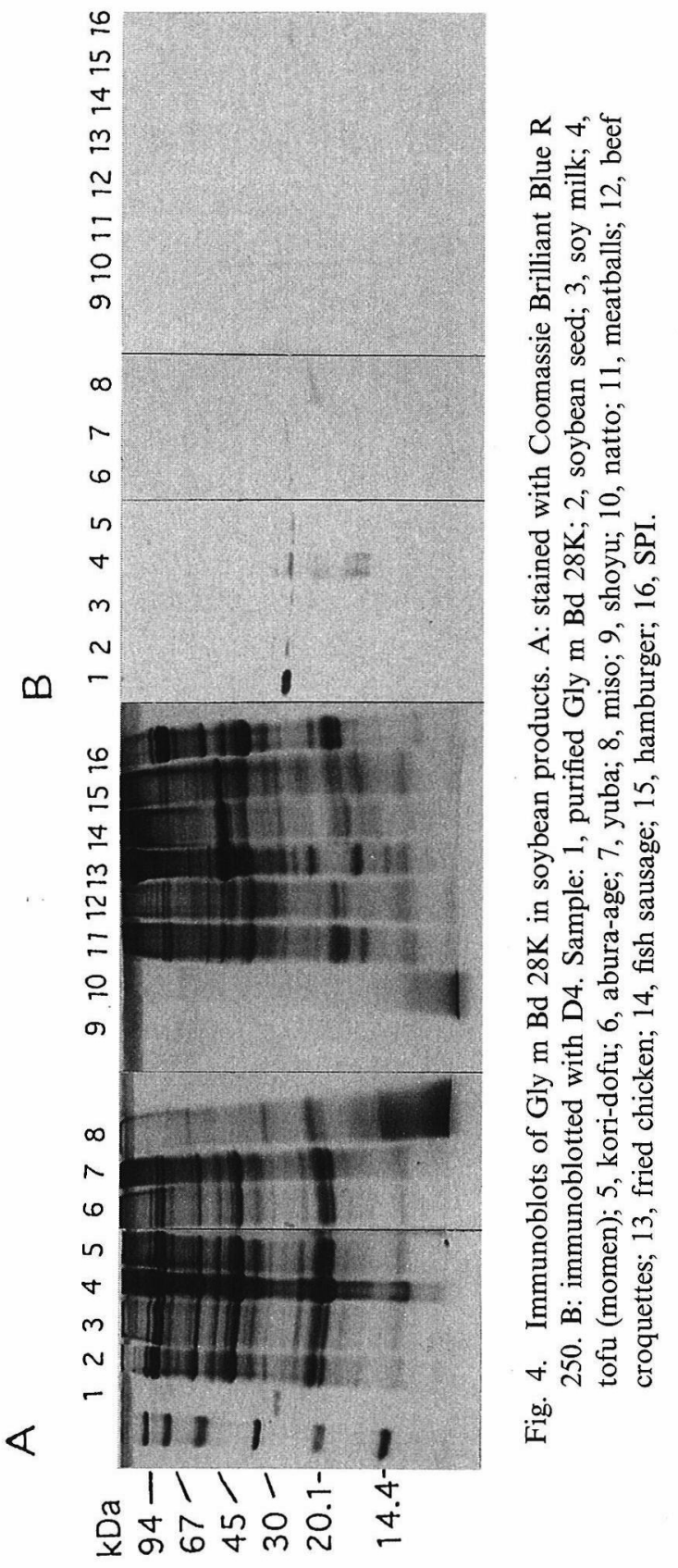


commercially as a drink was shown to contain a relatively low amount of allergen compared with fresh soy milk that had been made in our laboratory. The allergen in the commercial soy milk might be reduced during preparation. The reduction of the allergen in abura-age was considered to be due to denaturation under high temperature during processing. All the above-mentioned products were found to contain three orders less Gly m Bd $28 \mathrm{~K}$ than Gly m Bd $30 \mathrm{~K}$ (8). No Gly m Bd $28 \mathrm{~K}$ could be detected in the fermented soybean products, as shown in the case of Gly $\mathrm{m}$ Bd $30 \mathrm{~K}(8-10)$. Gly $\mathrm{m}$ Bd $30 \mathrm{~K}$ occurs at a significant concentration in meatballs, beef croquettes, and fried chicken, but no Gly $\mathrm{m} \mathrm{Bd} 28 \mathrm{~K}$ was shown to occur in the foods with SPI as additive in the present study. This suggests that Gly $\mathrm{m} \mathrm{Bd} 28 \mathrm{~K}$ may tend to be destroyed during the preparation of the products. The other processed foods, fish sausage and hamburger, also contained no Gly $\mathrm{m}$ Bd $28 \mathrm{~K}$.

To confirm these results obtained with the sandwich ELISA, the allergen in the soybean products was examined by using an immunoblotting technique with D4. Since D4 shows stronger affinity for the guanidine-denatured allergen than C5, D4 was used for the immunoblot analyses. Of the soybean products, the immunoblotting patterns of the allergen in tofu, yuba, abura-age, soy milk, natto, soy sauce, meatballs, fish sausage, and SPI, which had been obtained with C5, had been reported in the previous paper (1). These patterns were quite comparable with those obtained with D4 (Fig. 4). Soybean seed, soy milk, tofu, kori-dofu, abura-age, and yuba gave an intense band corresponding to the allergen, but the allergen in the fermented products could not be detected. Meatballs, beef croquettes, fried chicken, and hamburger were shown to contain no Gly m Bd 28K. Although miso gave an intense band corresponding to a peptide with a molecular mass of $21 \mathrm{kDa}$, the band was found to be due to a non-specific binding of peroxidase-conjugated anti-mouse IgM. In tofu, many peptides having molecular masses of less than $26 \mathrm{kDa}$ were bound by the antibody, indicating that these bands were obtained by nonspecific binding peroxidase-conjugated anti-mouse IgM. The immunoblotting analyses support the results obtained with the sandwich ELISA. These observations and the findings provide useful information to soybean-sensitive patients in the safe selection of soybean products. Furthermore, the sandwich ELISA forly $\mathrm{m} \mathrm{Bd} 30 \mathrm{~K}$ and $28 \mathrm{~K}$ will be useful tools for the in vitro evaluation of the allergenicity of soybean products.

\section{REFERENCES}

1) Tsuji H, Bando N, Hiemori M, Yamanishi R, Nishikawa K, Ogawa T. 1997. Purification and characterization of soybean allergen Gly m Bd 28K. Biosci Biotech Biochem 61: 942-947.

2) Ogawa T, Bando N, Tsuji H, Okajima H, Nishikawa K, Sasaoka K. 1991. Identification of the IgE-binding protein in soybeans by immunoblotting with the sera of the soybean-sensitive patients with atopic dermatitis. J Nutr Sci Vitaminol 37: 555-565. 
3) Ogawa T, Tsuji H, Bando N, Kitamura K, Zhn Y-L, Hirano H, Nishikawa K. 1993. Identification of the soybean allergic protein, Gly $\mathrm{m} \mathrm{Bd} 30 \mathrm{~K}$, with the soybean seed 34-kDa oil-body-associated protein. Biosci Biotech Biochem 57: 1030-1033.

4) Ogawa T, Bando N, Tsuji H, Nishikawa K, Kitamura K. 1995. $\alpha$-Subunit of $\beta$ conglycinin, an allergenic protein recognized by $\operatorname{IgE}$ antibodies of soybean-sensitive patients with atopic dermatitis. Biosci Biotech Biochem 59: 831-833.

5) Tsuji H, Bando N, Kimoto M, Okada N, Ogawa T. 1993. Preparation and application of monoclonal antibodies for a sandwich enzyme-linked immunosorbent assay for the major soybean allergen, Gly m Bd 30K. J Nutr Sci Vitaminol 39: 389-397.

6) Tsuji H, Ogawa T, Bando N, Kimoto M, Sasaoka K. 1990. A monoclonal antibody recognizing the FAD binding site of 4-aminobenzoate hydroxylase from Agaricus bisporus. J Biol Chem 265: 16064-16067.

7) Nakane PK, Kawaoi A. 1994. Peroxidase-labeled antibody. A new method of conjugation. J Histochem Cytochem 22: 1084-1091.

8) Tsuji H, Okada N, Yamanishi R, Bando N, Kimoto M, Ogawa T. 1995. Measurement of Gly $\mathrm{m} \mathrm{Bd} 30 \mathrm{~K}$, a major soybean allergen, in soybean products by a sandwich enzyme-linked immunosorbent assay. Biosci Biotech Biochem 59: 150-151.

9) Yamanishi R, Hung T, Tsuji H, Bando N, Ogawa T. 1995. Reduction of the soybean allergenicity by the fermentation with Bacillus natto. Food Sci Technol 1: 14-17.

10) Tsuji H, Okada N, Yamanishi R, Bando N, Ebine H, Ogawa T. 1997. Fate of a major soybean allergen, Gly m Bd 30K, in rice-, barley- and soybean-koji miso (fermented soybean paste) during fermentation. Food Sci Technol 3: 145-149.

11) AOAC. 1980. The Official Methods of Analysis of AOAC, 13th ed, p 14-15. 